\title{
Correction to: The interactions of ZDHHC5/
} GOLGA7 with SARS-CoV-2 spike (S) protein and their effects on $S$ protein's subcellular localization, palmitoylation and pseudovirus entry

Xiao-Tao Zeng, Xiao-Xi Yu and Wei Cheng ${ }^{*}$

\section{Correction to: Virology Journal (2021) 18:257}

https://doi.org/10.1186/s12985-021-01722-w

Following publication of the original article [1], the authors identified an error in the author name of Xiao-Xi Yu.

The incorrect author name is: Xiao-Ti Yu.

The correct author name is: Xiao-Xi Yu.

The author group has been updated above and the original article [1] has been corrected.

\section{Publisher's Note}

Springer Nature remains neutral with regard to jurisdictional claims in published maps and institutional affiliations.

Published online: 03 February 2022

\section{Reference}

1. Zeng, et al. Virol J. 2021;18:257. https://doi.org/10.1186/

s12985-021-01722-W. 